\title{
Study the Effect of Ruthenium Dye Layer on Negative Capacitance in Solar Cells Based on the $\mathrm{Nc}^{-\mathrm{TiO}_{2}}$ Semiconducting Polymer Heterojunction
}

\author{
H. Al-Dmour \\ Department of Physics, Faculty of Science, Mu'tah University, Mu'tah, Jordan \\ Email: $\underline{\text { hmoud203@gmail.com }}$
}

Received 27 September 2014; accepted 15 January 2015; published 21 January 2015

Copyright (C) 2015 by author and Scientific Research Publishing Inc.

This work is licensed under the Creative Commons Attribution International License (CC BY).

http://creativecommons.org/licenses/by/4.0/

\section{(c) (i) Open Access}

\begin{abstract}
We report the effect of ruthenium dye on negative capacitance of nanocrystalline titanium dioxide/poly(3-hexyl thiophene), nc- $\mathrm{TiO}_{2} / \mathrm{P} 3 \mathrm{HT}$, heterojunction solar cells. It has been found that the low frequency capacitance reaches a high positive value and then drop to the negative region. In $\mathrm{P3HT} / \mathrm{Ru}-\mathrm{Dye} / \mathrm{nc}^{-\mathrm{TiO}_{2}}$ solar cells, the negative capacitance is observed under very low forward bias condition unlike the negative capacitance in $\mathrm{P} 3 \mathrm{HT} / \mathrm{ncTiO}_{2}$ solar cells. That is attributed to the difference of the concentration of dipole and presence of depletion region at interface between the P3HT and nc- $\mathrm{TiO}_{2}$.
\end{abstract}

\section{Keywords}

Admittance Spectroscopy, Negative Capacitance, Forward Bias, Polarization

\section{Introduction}

The capacitance measurements have been conducted on organic/inorganic solar cells to understand the properties of materials and interfaces [1]-[5]. In the past decades, the negative capacitance phenomenon in organic/inorganic electronic devices has been observed and gains a lot of interests. One example of such devices is organic light emitting diode. C. Zhu reported [4] that the injection carrier's recombination occurred in active region added a negative contribution to the capacitance in OLED. According to Lungenshmeid's work [5], the organic solar cells based on P3HT and PCBM materials produce large negative capacitance. They have found that the appearance of negative capacitance in this device is associated with slow electron hole bimolecular recombina- 
tion at the heterojunction interfaces and the ambient conditions. Under illumination long lived photogenerated charges at the P3HT:PCBM interfaces increase electron-hole bimolecular recombination rate, which in turn renders the capacitance less negative. In our recent report [6], the negative capacitance of $\mathrm{P} 3 \mathrm{HT} / \mathrm{nc}-\mathrm{TiO}_{2}$ shows a dependence of the presence of air around the device. Under vacuum the negative capacitance gradually disappears with increasing the pressure in vacuum chamber. In 2013, Demet [2] found that the negative capacitance of $\mathrm{Au} / \mathrm{n}-\mathrm{GaAs}$ Schottky barrier diodes (SBDs) may be explained to the polarization especially at low frequencies and the introduction of more carriers in the structure. In addition to that, Xichang Bao [3] also observed the negative capacitance in GaN-based p-i-n photo detectors. In this device, the negative capacitance is mainly due to the carrier confinement of the deep level centers in the detector, which mainly includes lattice defects formed by high dose ion implantation and subsequent annealing. Therefore, a lot of works are conducted to explain the parameters which affect the negative capacitance. In organic/nc- $\mathrm{TiO}_{2}$ solar cells, no one studies the relationship between the presence of a dye at interface and the negative capacitance. The purpose of the present work is to investigate the appearance of negative capacitance in $\mathrm{P} 3 \mathrm{HT} / \mathrm{nc}-\mathrm{TiO}_{2}$ with and without dye.

\section{Experimental Procedures}

Figure 1 shows molecular structure of materials used in fabricated our solar cells. The devices studied here were composed of fluorine-doped tin oxide $\left(\mathrm{SnO}_{2}: \mathrm{Fn}\right)$ electrodes pre-coated with a thin compact layer of $\mathrm{TiO}_{2}$, deposited by spray pyrolysis, the nc- $\mathrm{TiO}_{2}$ (Ti-nanoxide $\mathrm{T}$ ) in the form of a sol-gel paste and the sensitizing dye ruthenium 535 (RuL2(NCS)2:2 TBA) all purchased from Solaronix Co., Switzerland, and P3HT from Sigma-Aldrich Ltd. These solar cells were fabricated as following procedures. The bottom layer of the device $\left(\mathrm{SnO}_{2}: \mathrm{F}+\right.$ compact $\mathrm{TiO}_{2}$ ) were cleaned properly by rubbing it with decon 90 soap and then held under tap water, hot water and ultrapure water subsequently. After drying the surface, a nc- $\mathrm{TiO}_{2}$ paste was then spread over the substrates using a doctor blade left for 20 minute in air until the milky color on the surface it disappear. Then it was cured were heated in stages up to $450^{\circ} \mathrm{C}$ and held at that temperature for $30 \mathrm{~min}$ before cooling to room temperature over $30 \mathrm{~min}$ to form the anatase phase. Typically, the resulting porous, $\mathrm{nc}-\mathrm{TiO}_{2}$ layer was $\sim 2 \mu \mathrm{m}$ thick soaking inside sensitizing dye ruthenium 535 (RuL2(NCS)2:2 TBA)-ethanol solution for 48 hours. The substrate was removed from the solution and rinsed in ethanol immediately and then dried under a nitrogen flow for three minutes. The p-type semiconductor (P3HT) was coated on the upper surface of $\mathrm{Ru}$ dye/nc- $\mathrm{TiO}_{2}$ layer using model 4000 photoresist Spinner. A drop of P3HT in chloroform $(15 \mathrm{mg} / \mathrm{mL})$ was allowed to suffuse into this layer for several seconds prior to spincoating at $1000 \mathrm{rpm}$. The top electrode with area of of $3 \mathrm{~mm}^{2}$ was formed with $50 \mathrm{~nm}$ thick gold deposition. In addition, two layer solar cells ( $\mathrm{P} 3 \mathrm{HT} / \mathrm{nc}-\mathrm{TiO}_{2}$ solar cells) consists of same materials in the above without Ru-dye were fabricated by following the same procedures.

For AC electrical characterisation, a Solartron 1260 Frequency was used. The capacitance and conductance were measured as a function of frequency from $100 \mathrm{~Hz}$ to $1 \mathrm{MHz}$ at a fixed voltage using a test signal of $50 \mathrm{mV}$. All AC measurements were conducted at room temperature. Capacitance-voltage measurements were also carried out within the range $+2.5 \mathrm{~V}$ to $-2.5 \mathrm{~V}$ at $0.1 \mathrm{~V}$ step at fixed frequencies of $100 \mathrm{~Hz}$. Finally, The voltage bias was applied on bottom electrode of SnO:Fn and make the device under forward bias from $0 \mathrm{~V}$ to $-2.5 \mathrm{~V}$ and under reverse bias condition from $+2.5 \mathrm{~V}$ to zero voltage.

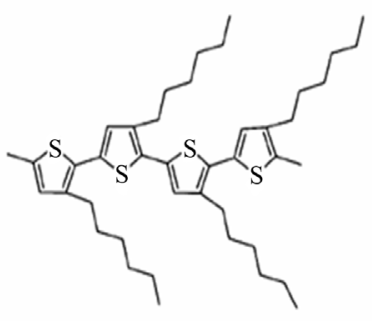

(a)

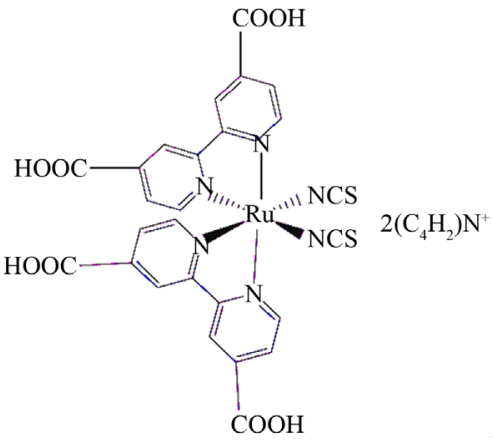

(b)

Figure 1. Structure of (a) P3HT and (b) ruthenium 535 (RuL2(NCS)2:2 TBA) dye. 


\section{Results}

Figure 2 and Figure 3 show the voltage dependence of the capacitance $C$ and conductance/angular frequency $(G / \omega)$ of P3HT/Ru dye/nc- $\mathrm{TiO}_{2}$ solar cells at fixed frequency of $100 \mathrm{~Hz}$. The $C$ and $(G / \omega)$ at the positive bias are almost constant and shows a weak dependence on voltage applied. That was expected because the device is under reverse bias condition. The $C$ and $(G / \omega)$ are dominated by electrical properties of the bulk region of device. Under negative bias condition (forward bias), the $C$ and $(G / \omega)$ curves are affected by the voltage applied on $\mathrm{SnO}_{2}$ electrode. A peak voltage in capacitance-voltage curve was observed around $-0.8 \mathrm{~V}$ and the capacitance is equal to $35 \mathrm{nF}$. When the voltage applied on the device was bigger than the peak voltage, the capacitance decrease to zero capacitance at $0.98 \mathrm{~V}$ and move to negative region to reach $-170 \mathrm{nF}$ at $-2.5 \mathrm{~V}$. Interestingly, the conductance/angular starts to grow up rapidly at $0.8 \mathrm{~V}$ where the peak of capacitance-voltage curve appeared. It was around $2260 \mathrm{nF}$ at $-0.8 \mathrm{~V}$ and increased to value of $31,100 \mathrm{nF}$ at $2.5 \mathrm{~V}$.

The measurements in the above were conducted on $\mathrm{P} 3 \mathrm{HT} / \mathrm{nc}-\mathrm{TiO}_{2}$ solar cells without dye. Figure 4 shows that the negative capacitance was observed at different value of negative bias voltage in comparison with $\mathrm{P} 3 \mathrm{HT} /$ dye/nc-TiO 2 solar cells. Under positive bias condition, the capacitance was low and did not respond to change in voltage bias applied on the device. The peak voltage in capacitance-voltage curve was obtained at high negative bias voltage around $-1.5 \mathrm{~V}$ at $100 \mathrm{HZ}$ and then the capacitance start to decrease to negative region. Besides the difference in capacitance-voltage $(\mathrm{C}-\mathrm{V})$ curve characteristics between the two devices, the conductance/angular frequency versus voltage $(G / W-V)$ characteristics was compared between them. Figure 5 shows that the $(G / \omega)$ was very low at reverses bias as expected and start to increase rapidly with high negative bias condition. The devices display low conductance/angular frequency in the absence of dye between the P3HT and nc- $\mathrm{TiO}_{2}$.

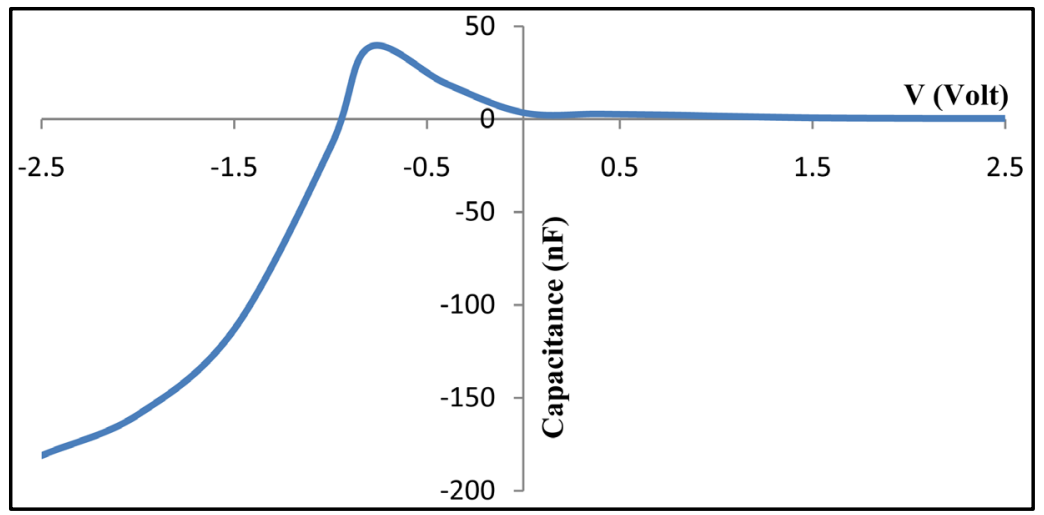

Figure 2. Capacitance-voltage characteristics of the P3HT/Ru-Dye/nc-TiO ${ }_{2}$ solar cells.

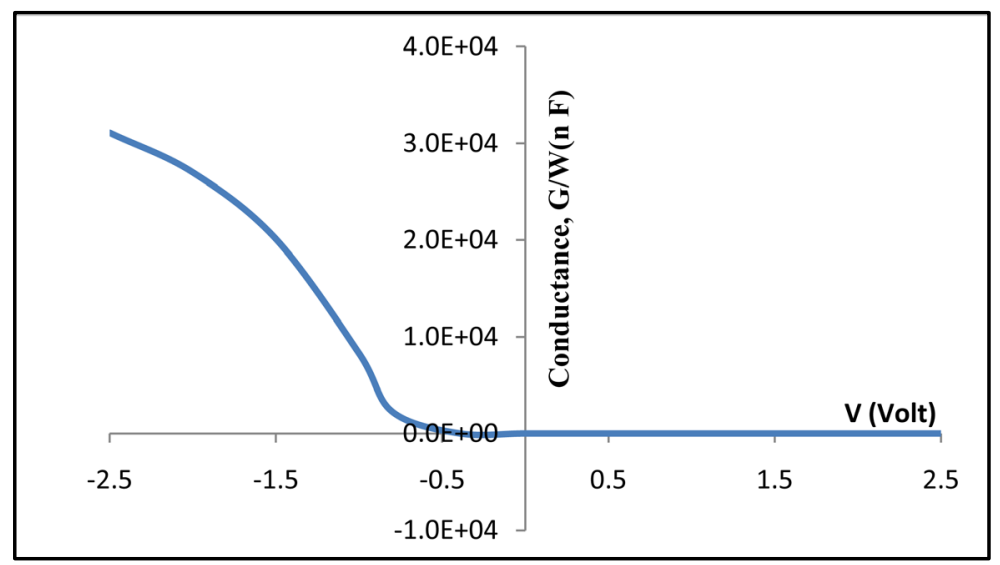

Figure 3. Conductance/Angular frequency-voltage characteristics of the P3HT/Ru-Dye/nc-TiO 2 solar cells. 


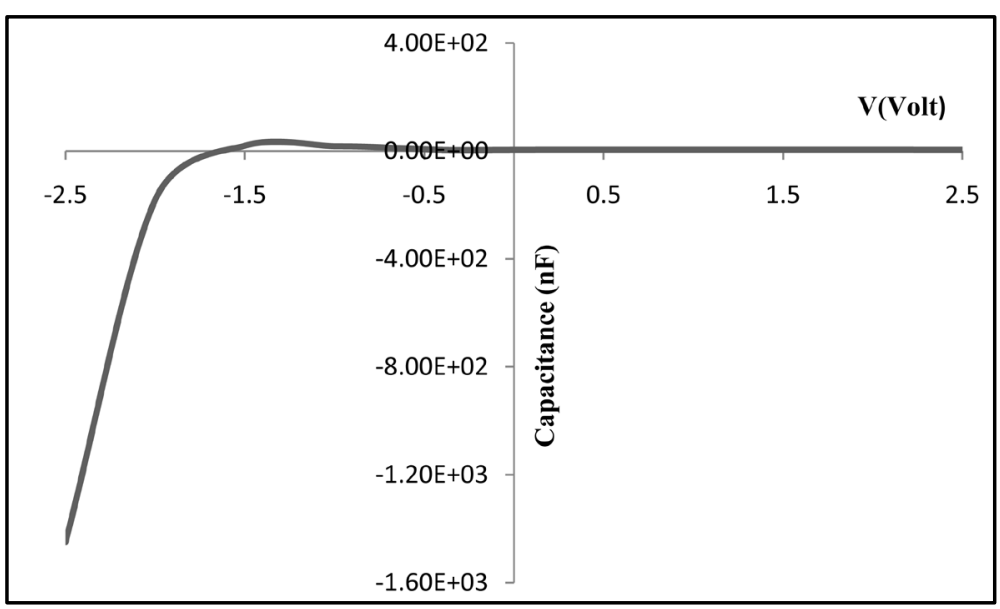

Figure 4. Capacitance-voltage characteristics of the $\mathrm{P} 3 \mathrm{HT} / \mathrm{nc}-\mathrm{TiO}_{2}$ solar cells.

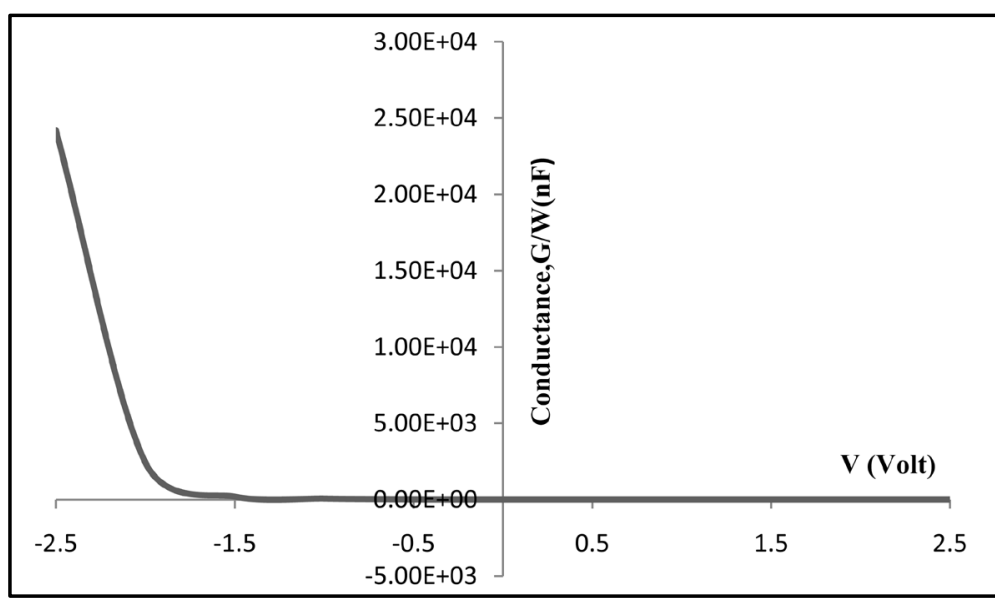

Figure 5. Conductance/Angular frequency-voltage characteristics of the $\mathrm{P} 3 \mathrm{HT} / \mathrm{nc}-\mathrm{TiO}_{2}$ solar cells.

To understand the differences in capacitance and conductance between the two devices, the measurements were also conducted on broader frequency range. Figure 6 shows the frequency dependence of capacitance of $\mathrm{P} 3 \mathrm{HT} /$ dye/nc- $\mathrm{TiO}_{2}$ solar cells at various applied voltage bias. The capacitance is weakly dependent on the high frequency in comparison with low frequency. For higher negative bias (above $-0.8 \mathrm{~V}$ ), the negative capacitance is observed and increase rapidly with 1) decrease of frequency and 2) increase of negative voltage bias. The high frequency capacitance corresponds to geometric capacitance between the two electrodes, the capacitance was low. In addition, the conductance-frequency characteristics of solar cells were also investigated at different biases in Figure 7. At zero bias voltage, the conductance was low in the whole frequency. The conductance at low frequency was increasing rapidly with decrease of negative bias especially when the frequency was below 1000 $\mathrm{Hz}$. This corresponds to forward bias and a high conduction current through the junction.

For P3HT/nc-TiO 2 solar cells, Figure 8 shows the capacitance versus frequency at different applied voltage. The results emphasis the effect of dye layer on appearance of negative capacitance phenomenon. Under high negative voltage $(-2 \mathrm{~V})$, the capacitance was only observed negative while in $\mathrm{P} 3 \mathrm{HT} / \mathrm{dye} / \mathrm{ncTiO}_{2}$ solar cells it was below $-1 \mathrm{~V}$. That accompanied also with difference in characterizes of conductance of $\mathrm{P} 3 \mathrm{HT} / \mathrm{nc}-\mathrm{TiO}_{2}$ versus frequency at different voltage in Figure 9. It was decreasing with increase of frequency on broader voltage range, the low frequency conductance increase rapidly and was lower than $\mathrm{P} 3 \mathrm{HT} / \mathrm{dye} / \mathrm{ncTiO}_{2}$ solar cells.

\section{Discussion}

The AC measurements (C-V, $(G / \omega)$ ) show classical behaviour of the Schottky diode in the high frequency 


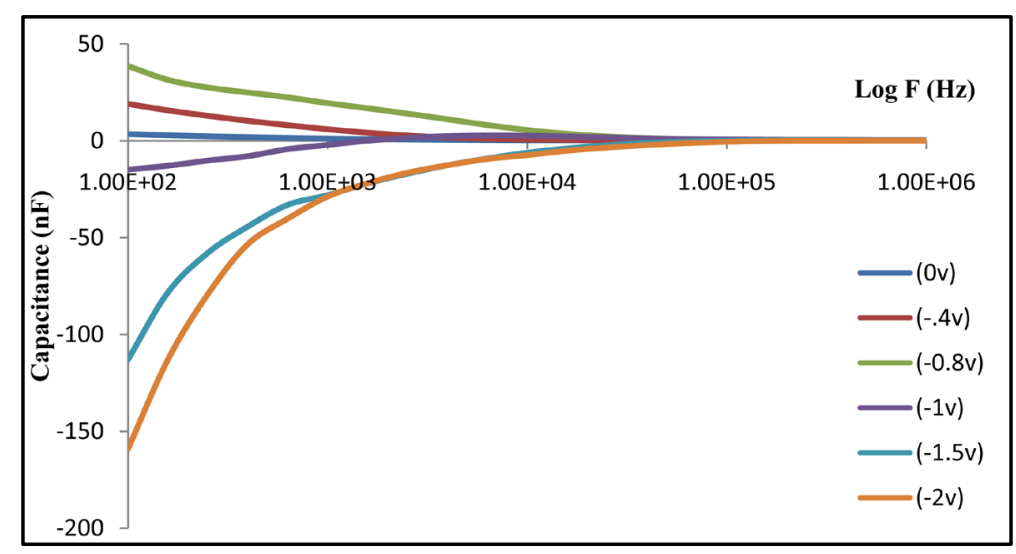

Figure 6. Capacitance-frequency characteristics of the P3HT/Ru-dye/nc- $\mathrm{TiO}_{2}$ solar cells for different voltages applied to the $\mathrm{SnO}_{2}$ :Fn electrode.

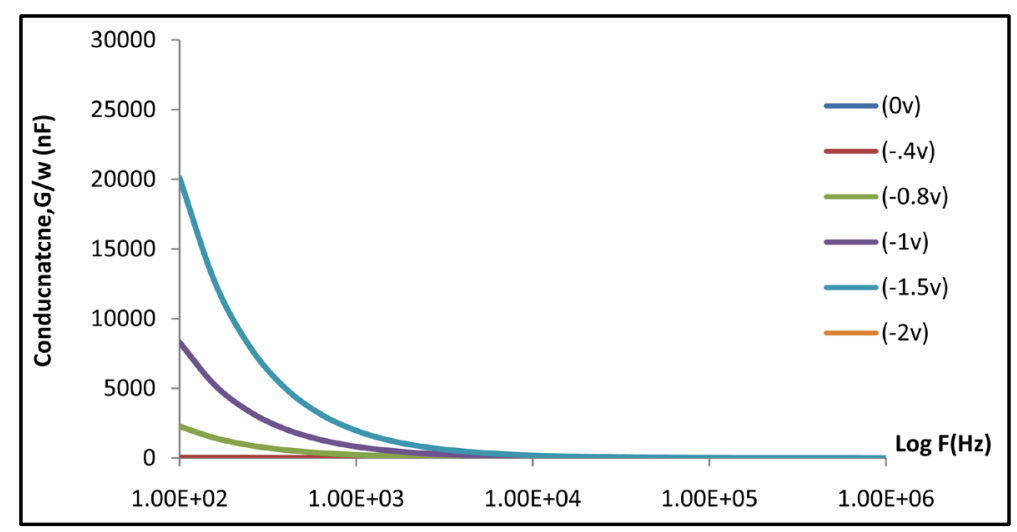

Figure 7. Conductance/Angular frequency-frequency characteristics of the $\mathrm{P} 3 \mathrm{HT} / \mathrm{Ru}$-dye/nc-TiO 2 solar cells for different voltages applied to the $\mathrm{SnO}_{2}$ :Fn electrode.

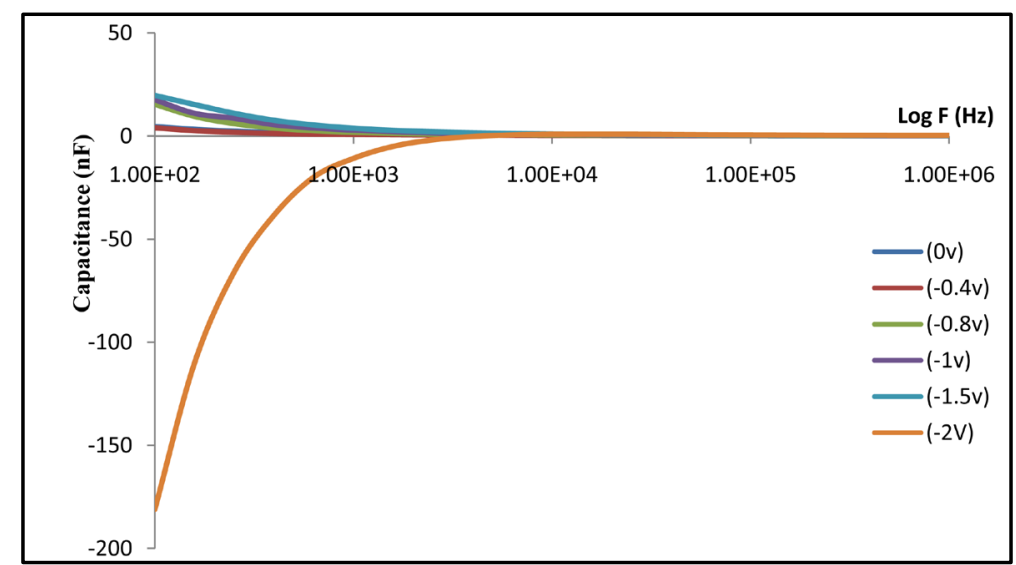

Figure 8. Capacitance-frequency characteristics of the $\mathrm{P} 3 \mathrm{HT} / \mathrm{nc}-\mathrm{TiO}_{2}$ solar cells for different voltages applied to the $\mathrm{SnO}_{2}: \mathrm{Fn}$.

where the capacitance is constant and increased to positive region [7]. Based on that, Figure 10 shows the equivalent circuit of our device. This circuit consists of three RC circuits connected on series. It is composed of 1) the bulk region of nc- $\mathrm{TiO}_{2}$ layer, 2) bulk region of P3HT layer and 3) the junction region between the P3HT and nc- $\mathrm{TiO}_{2}$. 


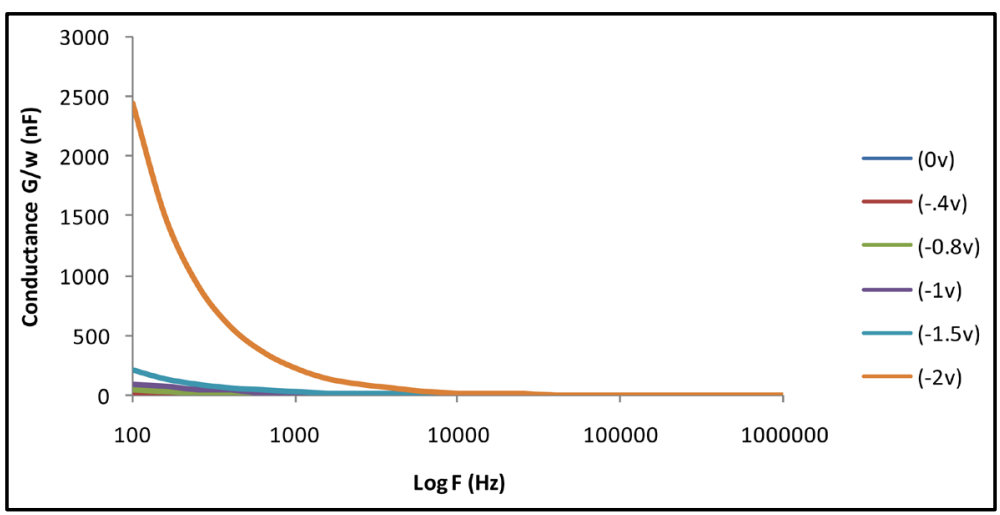

Figure 9. Conductance/Angular frequency-freqeuncy characteristics of the $\mathrm{P} 3 \mathrm{HT} / \mathrm{nc}-\mathrm{TiO}_{2}$ solar cells for different voltages applied to the $\mathrm{SnO}_{2}$ :Fn electrode.

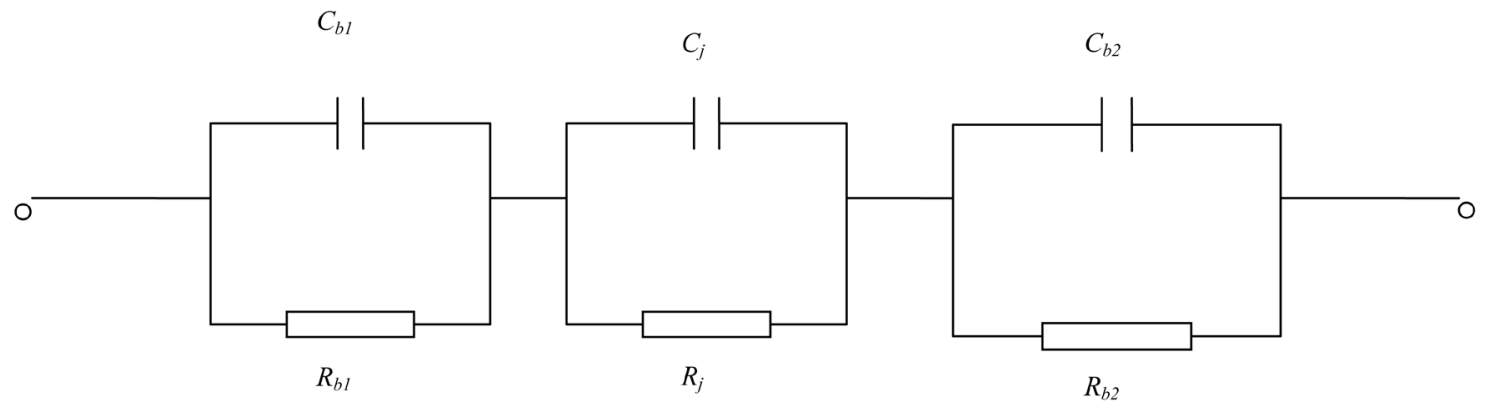

Figure 10. Equivalent circuits of the solar cells.

The total capacitance $\left(C_{\text {total }}\right)$ of our device is given by

$$
\frac{1}{C_{\text {total }}}=\frac{1}{C_{b 1}}+\frac{1}{C_{j}}+\frac{1}{C_{b 2}}
$$

where $C_{b 1}$ and $R_{b 1}$ represent capacitance and resistant of bulk region in nc- $\mathrm{TiO}_{2}, C_{b 2}$ and $R_{b 2}$ represent capacitance and resistant of bulk region in $\mathrm{P} 3 \mathrm{HT}$ and $C_{j}$ and $R_{j}$ represent capacitance and resistant of junction between the $\mathrm{P} 3 \mathrm{HT}$ and $\mathrm{nc}-\mathrm{TiO}_{2}$ layer. The high frequency capacitance $(f>10 \mathrm{KHz})$ of two devices was asymptotes to the horizontal axis and low. It corresponds to the bulk region capacitance because the junction capacitance is shunted by its resistance. In this case, the charge carriers in the bulk part of the device lag behind the ac voltage or simply fail to follow ac voltage. The capacitance was almost constant and low. On other hand, the difference in conductivity and permittivity between the $\mathrm{P} 3 \mathrm{HT}$ and $\mathrm{nc}-\mathrm{TiO}_{2}$ form interfacial polarization or Maxwell-Wagner Effect [8]. The low frequency-dielectric constant (capacitance) is dominated by the Maxwell Wanger relaxation given by

$$
\varepsilon^{\prime}=\frac{\varepsilon_{s}-\varepsilon_{\infty}}{\left(1+\omega^{2} \tau^{2}\right)}
$$

where the $\omega=2 \pi f$ is the angular frequency, $\tau$ is the relaxation time, $\varepsilon_{s}$ is static dielectric constants and $\varepsilon_{\infty}$ is high frequency dielectric constant. The capacitance at low frequency is sensitive to the applied bias voltage because the series resistance in bulk regions is high and shunt their capacitance. Therefore the, the total capacitance is determined by junction capacitance. As shown in Figure 2. It increases rapidly to reach a peak in positive region. Such behavior suggests that, Maxwell Wanger relaxation or polarization is occurred at interface [9]. This dispersion or increase in capacitance comes from the change in the properties of interfacial layer in our solar cells. In PEHT/nc-TiO ${ }_{2}$ solar cells, the junction capacitance is sum of depletion capacitance and diffusion capacitance on parallel give by equation 


$$
C_{j}=C_{\text {diff }}+C_{\text {depeltion }}
$$

The initial increase in capacitance and conductance are consistent with the decrease of the depletion region at interface between the $\mathrm{P} 3 \mathrm{HT}$ and nc- $\mathrm{TiO}_{2}$ layer. The junction capacitance or total capacitance is dominated by the depletion region capacitance. Subsequently, the carrier injection was less blocked and the current becomes barrier-unlimited, therefore the device was effectively in a good conductance state. With high forward bias at low frequency and collapse of depletion region, the diffusion capacitance contributes to the junction capacitance [10]. This capacitance depends on rearrangement of minority carriers injected at interface where the conduction becomes bulk-limited and the device is in its high conductance states. As result of that, the capacitance in P3HT/ nc- $\mathrm{TiO}_{2}$ solar cells require high forward bias to increase the capacitance rapidly to reach a peak and overcome the effect of depletion region on transportation of charge carrier though interface. Nevertheless, after the low frequency capacitance had reached a peak, it has decreased to negative region. According to report [9], the depletion region at interface produces large number of localized defect states where the injected charge carriers gets trapped. The carriers produced induced current by escaping them from traps under high forward bias. However the time requires hoping the carrier from their traps is very slow which cause to current to lags behind the voltage applied. That led to create inductive effective or negative capacitance. In addition, the dipole effect is created also at interface from hoping motion of detrapping carrier which also contributes to negative capacitance.

In $\mathrm{P} 3 \mathrm{HT} /$ dye/nc- $\mathrm{TiO}_{2}$ solar cells, the dye inserted between nc- $\mathrm{TiO}_{2}$ and $\mathrm{P} 3 \mathrm{HT}$ reduce the effect of depletion region at interface. The low frequency capacitance here is dominated only by diffusion capacitance. It is created by accumulating minority charge carrier at interface. Because of the dye layer, charge carriers move easily though through the junction and contribute to the total capacitance. The diffusion capacitance cause the rapidly increase in low forward capacitance to reach peaks under lower forward bias condition in comparison with $\mathrm{P} 3 \mathrm{HT} / \mathrm{nc}-\mathrm{TiO}_{2}$. In addition, dye layer adsorbed on $\mathrm{nc}-\mathrm{TiO}_{2}$ lead to form dipoles at interface with P3HT. The dipoles come from by 1) the protons which adsorb on the surface and carboxyl ate ion and 2) negatively charged thiocyanate legends of the dye. With increase the injection of charge carriers and the presence of dipole, the charge carrier get trapped with dipole. That leads to drop the capacitance to negative region at $-1 \mathrm{~V}$ while it was $-2 \mathrm{~V}$ for the $\mathrm{P} 3 \mathrm{HT} / \mathrm{nc}-\mathrm{TiO}_{2}$ [11]. That is attributed to the difference in concentration of dipoles at interface and the depletion region in the two devices.

\section{Conclusion}

In air, a low frequency negative capacitance of $\mathrm{P} 3 \mathrm{HT} / \mathrm{Ru}-$ dye/nc- $\mathrm{TiO}_{2}$ solar cells has been observed under very low forward bias condition in comparison with the $\mathrm{P} 3 \mathrm{HT} / \mathrm{nc}-\mathrm{TiO}_{2}$ solar cells. In addition, the conductance/angular frequency of solar cells with dyes was increased to $20,000 \mathrm{nF}$ while it was around 2500 for solar cells without dyes at -2 voltage bias. That difference is ascribed to the formation of dipoles by adding dye layer between the $\mathrm{P} 3 \mathrm{HT}$ and nc- $\mathrm{TiO}_{2}$ layers which cause lag more trapped charges with the voltage applied at interface and produce negative capacitance.

\section{Acknowledgements}

The authors thank the Prof Martin Taylor (Bangor University) for undertaking the AC measurements.

\section{References}

[1] Tina, A., Zhang, J., Wang, X., Yu, T. and Zou, Z. (2011) Influence of Capacitance Characteristic on I-V Measurement of Dye-Sensitized Solar Cells. Measurements, 44, 1551-1555.

[2] Demet, K., Abdulmecit, T. and Semsettin, A. (2013) The Origin of Negative Capacitance in Au/n-GaAs Schottky Barrier Diodes (SBDs) Prepared by Photolithography Technique in the Wide Frequency Range. Currrent Applied Physics, 13, 1101-1108. http://dx.doi.org/10.1016/j.cap.2013.03.001

[3] Bao, X.C., Xu, J.T., Li, C., Zhang, Y. and Li, X.Y. (2013) Temperature and Frequency Dependence of Negative Differential Capacitance in a Planar GaN-Based p-i-n Photodetector. Journal of Alloys and Compound, 581, 289-292. http://dx.doi.org/10.1016/j.jallcom.2013.07.098

[4] Zhu, C., Feng, L., Cong, H., Zhang, G. and Chen, Z. (2009) Negative Capacitance in Light-Emitting Devices. Solid State Electronics, 53, 324-328. http://dx.doi.org/10.1016/j.cplett.2006.02.060 
[5] Lungenschmied, C., Ehrenfreund, E. and Sariciftic, N.S. (2009) Negative Capacitance and Its Photo-Inhibition in Organic Bulk Heterojunction Devices. Organic Electronic, 10, 115-118. http://dx.doi.org/10.1016/j.orgel.2008.10.011

[6] Al-Dmour, H. (2014) Effect of Ambient Air Condition on Low Frequency Negative Capacitance of nc-TiO $2 / \mathrm{P3HT}$ Heterojuction Solar Cells. American Journal of Applied Science, 11, 351-1356. http://dx.doi.org/10.3844/ajassp.2014.1351.1356

[7] Taylor, D.M. and Gmoes, H.L. (1995) Electrical Characterization of the Rectifying Contact between Aluminium and Electrodeposited Poly(3-methylthiophene). Journal of Physics D: Applied Physics, 28, 2554-2560. http://dx.doi.org/10.1088/0022-3727/28/12/025

[8] von Hippel, A.R. (1954) Dielectrics and Waves. Wiley, Hoboken.

[9] Wnag, C.C., Liu, G.Z. and Lu, H.B. (2008) Low-Frequency Negative Capacitance in $\mathrm{La}_{0.8} \mathrm{Sr}_{0.2} \mathrm{MnO}_{3} / \mathrm{Nb}^{-D o p e d ~} \mathrm{SrTiO}$ Heterojunction. Applied Physics Letter, 92, 052905-052908. http://dx.doi.org/10.1063/1.2840195

[10] Lucia, M.L., Hernandez, R., Leon, C. and Martil, I. (1993) Capaictance Measurements of p-n Junition: Depletion Layer and Diffusions Capacitance Contribution. European Journal of Physics, 14, 85-89. http://dx.doi.org/10.1088/0143-0807/14/2/009

[11] Westermark, K., Henningsson, A., Rensmo, H., Soodergren, S., Siegbah, H. and Hagfeldt, A. (2002) Determination of the Electronic Density of States at a Nanostructured $\mathrm{TiO}_{2} / \mathrm{Ru}$-dye/Electrolyte Interface by Means of Photoelectron Spectroscopy. Chemical Physics, 285, 157-165. http://dx.doi.org/10.1016/S0301-0104(02)00699-7 
Scientific Research Publishing (SCIRP) is one of the largest Open Access journal publishers. It is currently publishing more than 200 open access, online, peer-reviewed journals covering a wide range of academic disciplines. SCIRP serves the worldwide academic communities and contributes to the progress and application of science with its publication.

Other selected journals from SCIRP are listed as below. Submit your manuscript to us via either submit@scirp.org or Online Submission Portal.
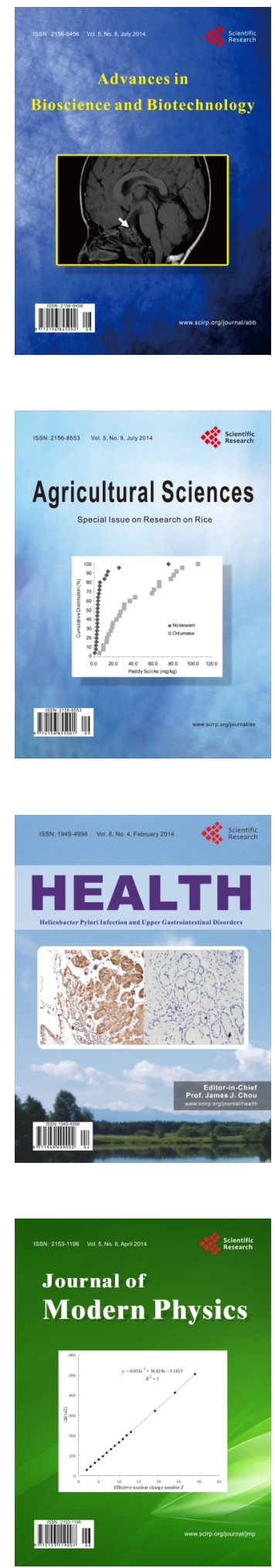
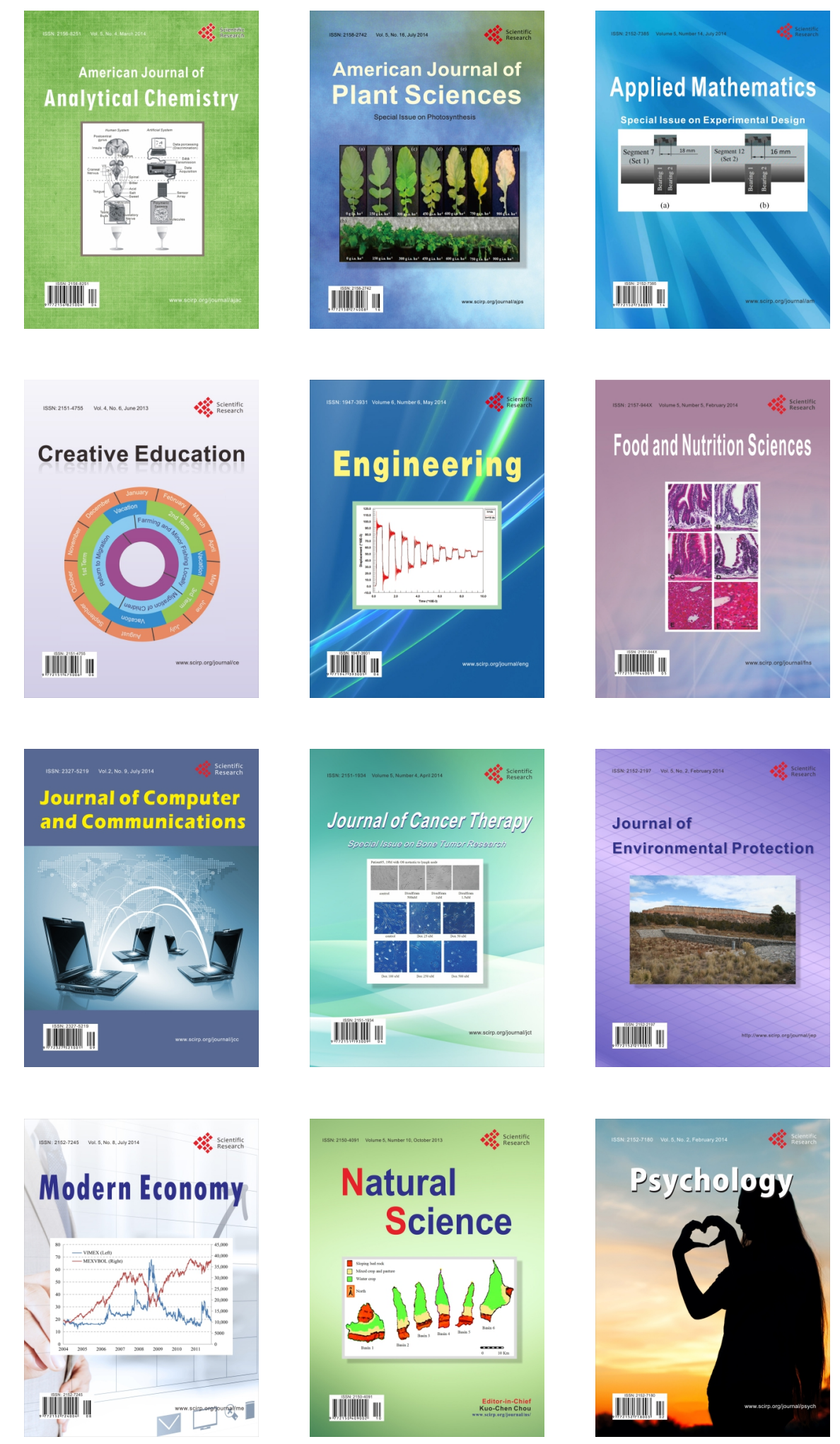